\title{
Lenalidomide increases human dendritic cell maturation in multiple myeloma patients targeting monocyte differentiation and modulating mesenchymal stromal cell inhibitory properties
}

\author{
Federica Costa ${ }^{1}$, Rosanna Vescovini ${ }^{1}$, Marina Bolzoni ${ }^{1}$, Valentina Marchica ${ }^{1}$, Paola \\ Storti $^{1}$, Denise Toscani ${ }^{1}$, Fabrizio Accardi ${ }^{1,2}$, Laura Notarfranchi ${ }^{1,2}$, Benedetta Dalla \\ Palma $^{1,2}$, Cristina Manferdini ${ }^{3}$, Sabrina Manni ${ }^{4}$, Giannalisa Todaro ${ }^{1}$, Gina Lisignoli ${ }^{3}$, \\ Francesco Piazza4, Franco Aversa ${ }^{1,2}$ and Nicola Giuliani ${ }^{1,2}$ \\ ${ }^{1}$ Department of Medicine and Surgery, University of Parma, Parma, Italy \\ ${ }^{2}$ Hematology and BMT Center, Azienda Ospedaliero-Universitaria di Parma, Parma, Italy \\ ${ }^{3}$ Laboratory of Immunorheumatology and Tissue Regeneration, Istituto Ortopedico Rizzoli, Bologna, Italy \\ ${ }^{4}$ Department of Medicine, Hematology Branch, University of Padova and Venetian Institute of Molecular Medicine, Padova, Italy \\ Correspondence to: Nicola Giuliani, email: nicola.giuliani@unipr.it \\ Keywords: multiple myeloma, dendritic cells, lenalidomide, mesenchymal stromal cells, immunomodulation \\ Received: December 14, $2016 \quad$ Accepted: May 10, $2017 \quad$ Published: May 23, 2017 \\ Copyright: Costa et al. This is an open-access article distributed under the terms of the Creative Commons Attribution License 3.0 (CC BY 3.0), \\ which permits unrestricted use, distribution, and reproduction in any medium, provided the original author and source are credited.
}

\section{ABSTRACT}

The use of Lenalidomide (LEN), to reverse tumor-mediated immune suppression and amplify multiple myeloma-specific immunity is currently being explored. Particularly, LEN effects on dendritic cells (DCs) are still unclear. In this study, we investigated the potential effect of LEN on DC differentiation and activity. DCs were differentiated either from $\mathrm{CD14}{ }^{+}$cells obtained from patients with multiple myeloma or from a human monocytic cell line.

LEN, at the concentration range reached in vivo, significantly increased the median intensity expression of HLA-DR, CD86 and CD209 by DCs derived from both bone marrow and peripheral myeloma monocytes and enhanced the production of Interleukin-8, C-C motif chemokine ligand (CCL) 2, CCL5 and tumor necrosis factor-a. Consistently, LEN pre-treated DCs showed an increased ability to stimulate autologous $\mathrm{CD}^{+}$cell proliferation. LEN effect on dendritic differentiation was associated with the degradation of the Cereblon-related factors Ikaros and Aiolos. Moreover, we showed that LEN also blunted mesenchymal stromal cell inhibitory effect on dendritic differentiation, inhibiting Casein Kinase-1a levels. Finally, in vitro data were confirmed in ex vivo cultures obtained from relapsed myeloma patients treated with LEN, showing a significant increase of DC differentiation from peripheral blood monocytes.

In conclusion, LEN increased the expression of mature dendritic markers both directly and indirectly and enhanced DC ability to stimulate $T$ cell proliferation and to release chemokines. This suggests a new possible mechanism by which LEN could exert its anti-myeloma activity. 


\section{INTRODUCTION}

The Immunomodulatory drugs (IMiDs $\left.{ }^{\circledR}\right)$ are a group of therapeutic agents, Thalidomide-derivatives, including Lenalidomide (LEN) and Pomalidomide (POM). The development of these drugs represented a paradigm shift in the treatment of multiple myeloma (MM) $[1,2]$. LENbased regimen is one of the standard of care for MM patients either in frontline or in relapsed setting [3-5]. Moreover, LEN has shown a significant impact on the progression free survival in maintenance after autologous stem cell transplantation [6].

Several mechanisms of action have been described, $[7,8]$ including immunomodulatory effects as $\mathrm{T}$ helper 1 cell activation, $\mathrm{T}$ regulatory cell ( $\mathrm{T}$ reg) suppression, and the induction of antibody-dependent cellular cytotoxicity (ADCC) by natural killer (NK) cells [9]. The molecular mechanisms involved in the anti-MM effect of $\mathrm{IMiDs}^{\mathbb{R}}$ have been recently elucidated highlighting the role of Cereblon (CRBN) and its target factors $[10,11]$. LEN binds CRBN in MM cells and causes selective ubiquitination and degradation, by the CRBN-CullinRING E3 ubiquitin ligase (CRL) 4 complex, of two lymphoid transcription factors essential for MM survival, Ikaros and Aiolos [12]. Through the same mechanism, LEN enhances T cell proliferation and interleukin (IL)-2 production. The loss of Ikaros and Aiolos is necessary and sufficient for LEN therapeutic effect [13]. Recently, it has been also reported a distinct CRBN substrate, Casein Kinase 1 alpha (CK1- $\alpha$ ) that is ubiquitinated and degraded after LEN treatment in myelodysplastic syndrome (MDS) with deletion of chromosome $5 \mathrm{q}(\operatorname{del}(5 \mathrm{q}))$ [14] and in $\mathrm{MM}$, as reported by Manni S et al. [15].

Currently, few data are reported on the possible effects of LEN on dendritic cells (DCs) populations. [9, 16-18] Interestingly, it has been shown that DCs from peripheral blood (PB) were functionally defective in MM patients, since they had decreased expression of maturation markers and antigen presentation capacity $[19,20]$. Nevertheless, it is not known which is the role of DCs in the anti-MM effect of LEN.

Different studies reported an increased incidence of acute Graft versus host disease (aGvHD), with a possible enhancement of the graft versus MM effect, in patients treated with LEN after allo-transplantation [21-23]. Since it is known that host and donor DCs are critical in the development of GvHD and also involved in the immunosuppressive properties of mesenchymal stromal cells (MSCs); [24-26] it is conceivable that LEN affects DCs.

Based on these evidences, in this study we investigated whether LEN may affect maturation, phenotype and functionality of DCs as antigen presenting cells (APCs), either directly or through the modulation of human mesenchymal stromal cell (hMSC) effect on DCs.

\section{RESULTS}

\section{LEN enhanced in vitro DC differentiation from both bone marrow (BM) and PB monocytes of MM patients and increased their chemokine and cytokine production degrading Ikaros and Aiolos}

We analyzed the expression of DC maturation markers on monocytes derived-DCs (mo-DCs) differentiated from BM aspirates and $\mathrm{PB}$ of MM patients. Despite a reduction of both number and \% of mature DCs, LEN, at the concentration range reached in vivo in MM patients, [27] significantly increased the expression, by DCs derived from BM, of HLA-DR (mean median fluorescence intensity (MFI) \pm standard error of the mean (SEM): DMSO vs LEN $0.1 \mu \mathrm{M}, 45.82 \pm 4.55$ vs $59.45 \pm 8.21$, $p=0.029 ;$ DMSO vs LEN $1 \mu \mathrm{M}, 45.82 \pm 4.55 v s$ $73.52 \pm 7.71, p=0.001$ ), CD86 (mean MFI \pm SEM: DMSO vs LEN $0.1 \mu \mathrm{M}, 137.58 \pm 22.83$ vs $177.76 \pm 27.04, p=0.036$; DMSO vs LEN $1 \mu \mathrm{M}, 137.58 \pm 22.83$ vs $223.38 \pm 32.26$, $p=0.003$ ) and CD209 (mean MFI \pm SEM: DMSO $v s$ LEN $0.1 \mu \mathrm{M}, 155.80 \pm 21.06$ vs $190.73 \pm 25.35, p=0.004)$ ( $p$ calculated by paired Student's $t$-test) (Figure 1A), compared to vehicle (DMSO). Flow-cytometry histograms from one representative MM patient were reported in Supplementary Figure 1A.

Similarly to BM derived DCs, increased CD86 (mean MFI \pm SEM: DMSO vs LEN $0.1 \mu \mathrm{M}$, $147.49 \pm 45.08$ vs $200.44 \pm 44.22, p=0.002$; DMSO vs LEN $1 \mu \mathrm{M}, 147.49 \pm 45.08 v s 249.61 \pm 42.10, p=0.016$ ) and CD209 (mean MFI \pm SEM: DMSO vs LEN $0.1 \mu \mathrm{M}$, $128.69 \pm 18.09$ vs $204.88 \pm 33.54, p=0.008$; DMSO vs LEN $1 \mu \mathrm{M}, 128.69 \pm 18.09 v s 196.32 \pm 36.33, p=0.023$ ) ( $p$ calculated by paired Student's $t$-test) expression was found in DCs differentiated from $\mathrm{PB} \mathrm{CD} 14^{+}$cells (Figure 1B). Flow-cytometry histograms from one representative patient were reported in Supplementary Figure 1B. Any significant differences between BM and PB samples of the same patient were found on LEN effect on DC maturation markers (2way ANOVA) (data not shown).

Interestingly, the increased expression of DC maturation markers was abrogated when LEN was used in combination with Dexamethasone (Dex) at $10^{-8} \mathrm{M}$ (Dex $v s$ LEN $0.1 \mu \mathrm{M}+$ Dex $v s$ LEN $1 \mu \mathrm{M}+$ Dex median MFI, HLA-DR: 129.5 vs 103.9 vs 109.9; CD86: 199 vs 237.4 vs 233.5; CD80: 115 vs 104.6 vs 90.24; CD209: 50.28 vs 52.58 vs 54.91, no statistically significant differences) (Friedman test) (Figure 2). Moreover, the addition of Dex dramatically decreased the number of DCs (median number: LEN $0.1 \mu \mathrm{M}+$ Dex vs LEN $0.1 \mu \mathrm{M}, 17238 v s$ 43568, $p<0.05$; LEN $1 \mu \mathrm{M}+$ Dex $v s$ LEN $1 \mu \mathrm{M}, 14028$ vs 43283, $p<0.05$ ) and the percentage of DCs obtained in vitro (median DC\%: LEN $0.1 \mu \mathrm{M}+$ Dex vs LEN $0.1 \mu \mathrm{M}$, $9.85 v s$ 25.90, $p<0.05$; LEN $1 \mu \mathrm{M}+$ Dex $v s$ LEN $1 \mu \mathrm{M}$, 
11.69 vs 19.9, $p<0.05)$ ( $p$ calculated by Wilcoxon test) (Figure 2).

Then we investigated the potential effect of LEN treatment on cytokine production by BM DCs using a Multiplex ELISA assay. We found that LEN treatment enhanced the production of IL-8 (median concentration, DMSO vs LEN 0.1 $\mu \mathrm{M}$ vs LEN $1 \mu \mathrm{M}$ : 1076 vs 1755 vs $2193 \mathrm{pg} / \mathrm{ml}, p<0.05), \mathrm{CC}$ chemokine ligand (CCL)2 (median concentration, DMSO vs LEN $0.1 \mu \mathrm{M} v s$ LEN 1 $\mu \mathrm{M}: 1355$ vs 2414 vs $2831 \mathrm{pg} / \mathrm{ml}, p<0.05$ ), CCL5 (median concentration, DMSO $v s$ LEN $0.1 \mu \mathrm{M} v s$ LEN $1 \mu \mathrm{M}: 49.68$ vs 64.48 vs $96.94 \mathrm{pg} / \mathrm{ml}, p<0.05)$ and TNF- $\alpha$ (median concentration, DMSO $v s$ LEN $0.1 \mu \mathrm{M} v s$ LEN $1 \mu \mathrm{M}: 684.4$ vs 965.4 vs $1101 \mathrm{pg} / \mathrm{ml}, p<0.05)$ and slightly decreased the production of IL- 6 (median concentration, DMSO vs LEN $0.1 \mu \mathrm{M} v s$ LEN $1 \mu \mathrm{M}$ : 60.97 vs 60.30 vs 47.74 pg/ml, $p<0.05)$ ( $p$ calculated by Friedman test), by mo-DCs differentiated from MM patients, compared to vehicle (Figure 3).

Based on the literature data showing that LEN exerts the anti-MM activity through the selective ubiquitination and degradation of Cereblon targets, Ikaros and Aiolos
A
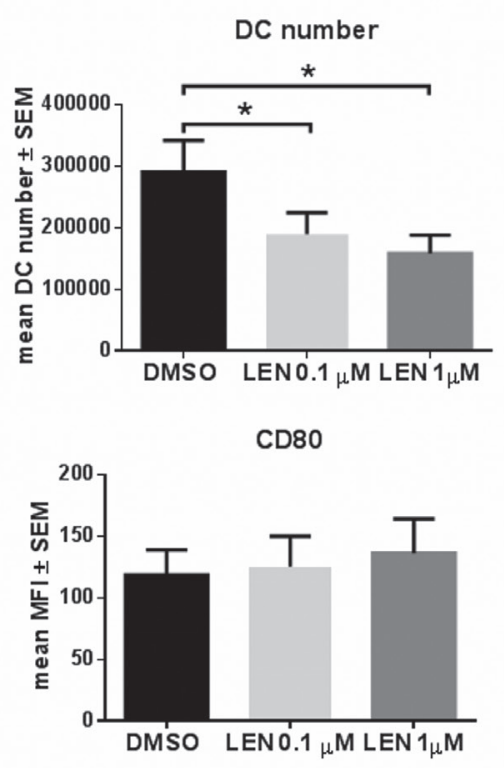

B
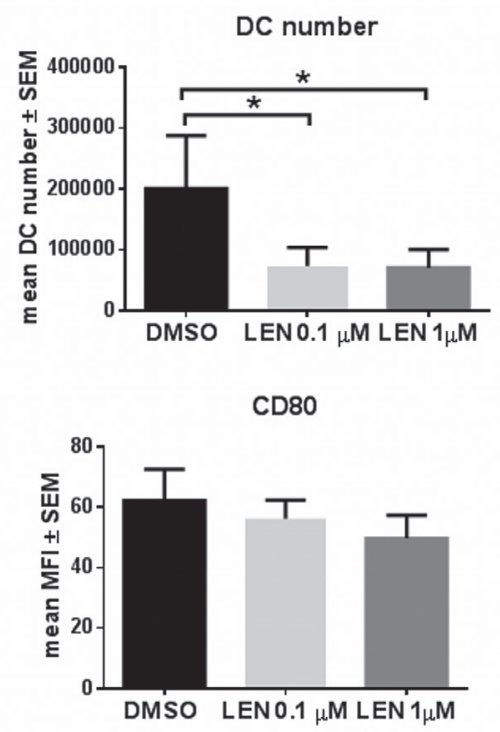
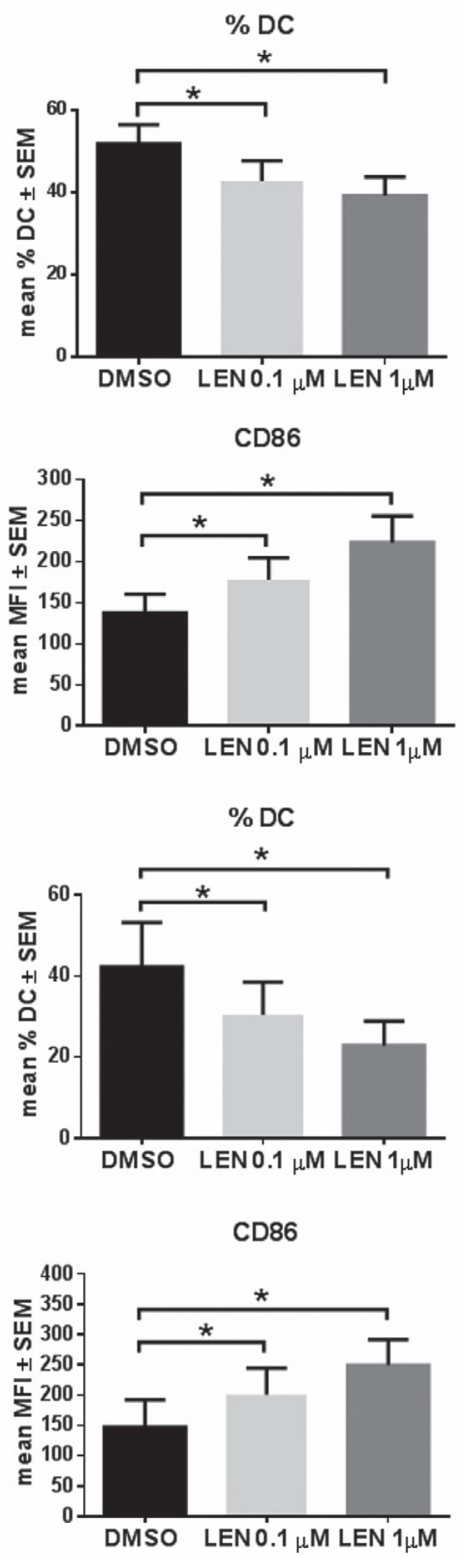

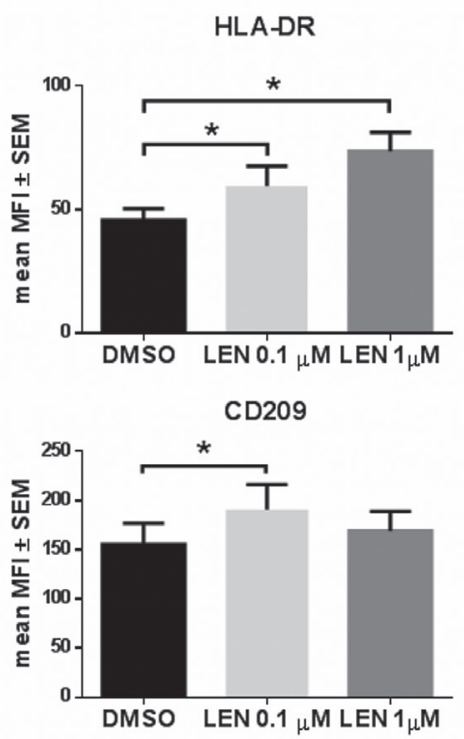

HLA-DR
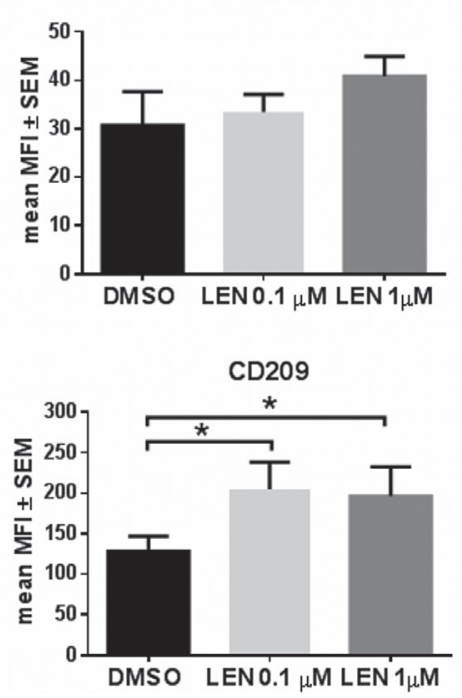

Figure 1: LEN enhanced in vitro DC differentiation from both BM and PB of MM patients. (A) DCs were differentiated from $\mathrm{BM} \mathrm{CD} 14^{+}$cells of MM patients, cultured in RPMI 10\% FBS with IL-4 and GM-CSF, for 8 days, in presence of LEN (0.1 and $1 \mu \mathrm{M})$ or DMSO. TNF- $\alpha$ was added in the last $24 \mathrm{~h}$ of differentiation period. Non-adherent cells were collected and analysed by flowcytometry for DC maturation markers. Graph bars represent the mean of DC number and \% and median fluorescent intensity (MFI) of DC maturation markers \pm standard error of the mean (SEM) ( $p$ calculated by paired Student's $t$-test) of 19 independent experiment. (B) DCs were differentiated from PB of 6 MM patients, following the same protocol. Graph bars represent the mean of DC number and \% and MFI of DC maturation markers $\pm \operatorname{SEM}$ ( $p$ calculated by paired Student's $t$-test). 
[12], we assessed the protein levels of Cereblon, Ikaros and Aiolos on LEN-treated THP1-DCs. We showed that THP1-DCs expressed Cereblon (Figure 4A) and that LEN treatment down-regulated Ikaros protein levels in a dose-dependent manner (Figure 4B). Moreover, we found that the basal Aiolos protein level was very low in THP1DCs and LEN further decreased its expression in these cells (Figure 4C). We also tested the effect on two other Cereblon targets, Interferon regulatory factor (IRF) 4 and Sequestosome-1/SQSTM1 (p62), that were respectively down-regulated [28] and up-regulated [29] after LEN treatment in MM cells. We showed that THP1-DCs did not express IRF4 (Figure 4D) and LEN did not affect p62 in THP-1 DCs (Figure 4E).

\section{LEN enhanced DC ability to stimulate autologous $\mathrm{CD3}^{+}$cell proliferation}

Next we evaluated whether the effect of LEN on DC maturation may affect DC functional properties. In order to evaluate LEN effect on DC ability to stimulate
$\mathrm{T}$ cell proliferation, DCs differentiated from BM of 4 MM patients, were tested as stimulators in the autologous Mixed Lymphocyte Reaction (MLR) assay in the presence of LEN or vehicle.

Interestingly, $\mathrm{CD}^{+}$cell proliferation was significantly higher in co-culture with LEN-treated DCs, compared to DMSO-treated DCs (median OD: DMSO vs LEN $0.1 \mu \mathrm{M}, 225$ vs 292, $p=0.0279$; DMSO vs LEN $1 \mu \mathrm{M}, 225$ vs 299, $p=0.0045)$ ( $p$ calculated by MannWhitney test) (Figure 5A). However, this effect was abrogated in the presence of Dex at $10^{-8} \mathrm{M}$ (median OD: LEN $0.1 \mu \mathrm{M}+$ Dex vs LEN $0.1 \mu \mathrm{M}, 263$ vs 470, $p=0.0043$; LEN 0.1 $\mu \mathrm{M}$ vs Dex, 470 vs 320, $p=0.0043$; LEN $1 \mu \mathrm{M}+$ Dex $v s$ LEN $1 \mu \mathrm{M}, 309 v s$ 446.5, $p=0.0317$; LEN $1 \mu \mathrm{M} v s$ Dex, 446.5 vs 320, $p=0.0159$ ) ( $p$ calculated by Mann-Whitney test) (Figure 5B).

\section{LEN blunted hMSC inhibitory properties on DC differentiation inhibiting CK1- $\alpha$ levels}

To investigate a possible MSC-mediated indirect effect of $\mathrm{LEN}$ on DCs, BM CD14 ${ }^{+}$cells of MM patients were
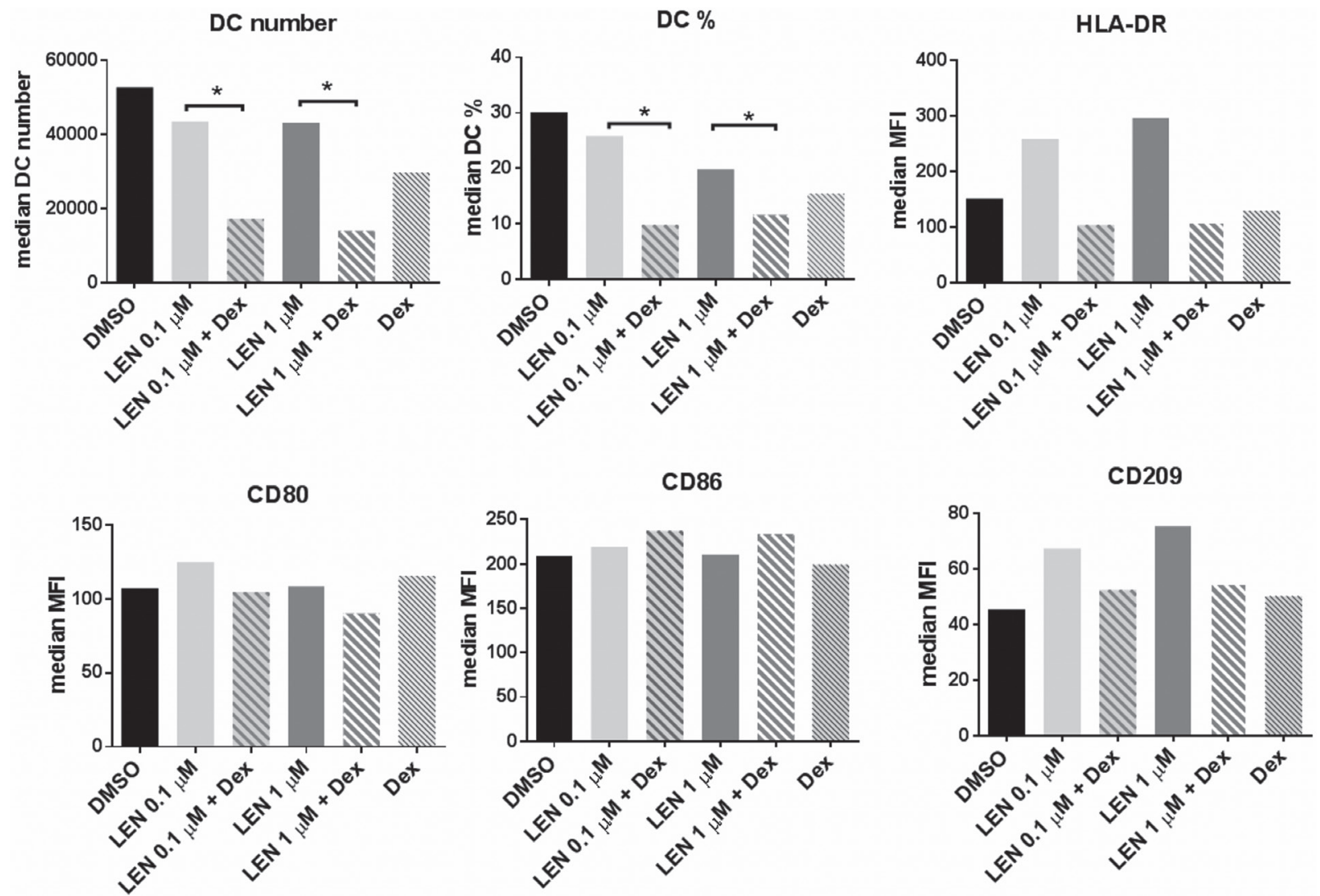

Figure 2: LEN effects on DC maturation markers were abrogated by Dex. DCs were differentiated from BM CD14 cells of MM patients, in the presence of LEN $(0.1$ and $1 \mu \mathrm{M})$ or DMSO, as reported in Materials and Methods. At the end of culture period, cells were collected and reseeded $\left(5 \times 10^{4} / \mathrm{ml}\right)$ in fresh medium with Dex $\left(10^{-8} \mathrm{M}\right)$ or vehicle $(\mathrm{EtOH})$ for $48 \mathrm{~h}$. After Dex treatment, cells were collected and analyzed for DC maturation markers. Graph bars represent the median of DC number and \% and MFI of DC maturation markers from 4 independent experiments ( $p$ calculated by Wilcoxon test). 
differentiated into DCs in the presence of LEN or DMSO treated human telomerase reverse transcriptase transduced hMSC (hTERT-hMSC) conditioned medium (CM).

We firstly demonstrated that hTERT-hMSC CM decreased DC maturation marker expression in this in vitro system (Figure 6A); then we found that LEN treatment reverted this effect, by increasing HLA-DR (median MFI, DMSO vs LEN 0.1 $\mu \mathrm{M} v s$ LEN $1 \mu \mathrm{M}$ : 19.88 vs $27.88 v s$ $31.34, p<0.05$ ) and CD86 (median MFI, DMSO vs LEN $0.1 \mu \mathrm{M} v s$ LEN $1 \mu \mathrm{M}: 30.78$ vs 37.52 vs 57.25, $p<0.05$ ) ( $p$ calculated by Friedman test) (Figure 6B).

Thereafter, we examined whether LEN treatment affected the expression of immunosuppressive factors in hTERT-hMSCs, by Real-time PCR (RT-PCR). Interestingly, we found that LEN significantly down-regulated prostaglandine 2 (PTGS2) gene expression levels at all tested concentrations (LEN $0.1 \mu \mathrm{M} v s$ DMSO, $p=0.0326$; LEN $1 \mu \mathrm{M}$ $v s$ DMSO, $p<0.0001$ ) (Figure 6C) but not indoleamine 2,3-dioxygenase 1 (IDO1), IL6, CCL5 and transforming growth factor beta 1 (TGFB1).

To investigate the molecular mechanism involved in the effect of LEN on MSCs, firstly we checked the expression profile of Cereblon and its target proteins in hTERT-hMSCs showing that they expressed Cereblon (Figure 7A) but not Ikaros, Aiolos and IRF4 (Figure 7B). We then focused our attention on another Cereblon substrate, CK1- $\alpha$. [14] LEN, at the higher concentration, decreased CK1- $\alpha$ protein level in hTERT-hMSCs (Figure 7C). We also found that LEN treatment did not affect p62 protein level, as observed in THP1- DCs (Figure 7D).

To better clarify the correlation between the decreased CK1- $\alpha$ levels in hMSCs after LEN treatment and LEN effect on the immunosuppressive properties of MSCs on DCs, we down-regulated CK1 $\alpha$ in hTERThMSCs through an IPTG inducible shRNA. We firstly checked CK1- $\alpha$ down-regulation by western blotting (Supplementary Figure 3A) and then we used the CM for in vitro $\mathrm{DC}$ differentiation from $\mathrm{BM} \mathrm{CD} 14^{+}$cells of $2 \mathrm{MM}$ patients. Interestingly, we found that the effect of hTERT-hMSCs on DC maturation markers were reverted by the down-regulation of CK1- $\alpha$ (mean MFI \pm SEM: CNT vs wt hTERT-hMSCs vs hTERT-hMSCs 6044, HLADR: $108.8 \pm 34.49$ vs $76.74 \pm 14.66$ vs $106.7 \pm 51.49$; CD86: $103.7 \pm 2.8$ vs $111.9 \pm 2.5$ vs $177 \pm 15.87$;
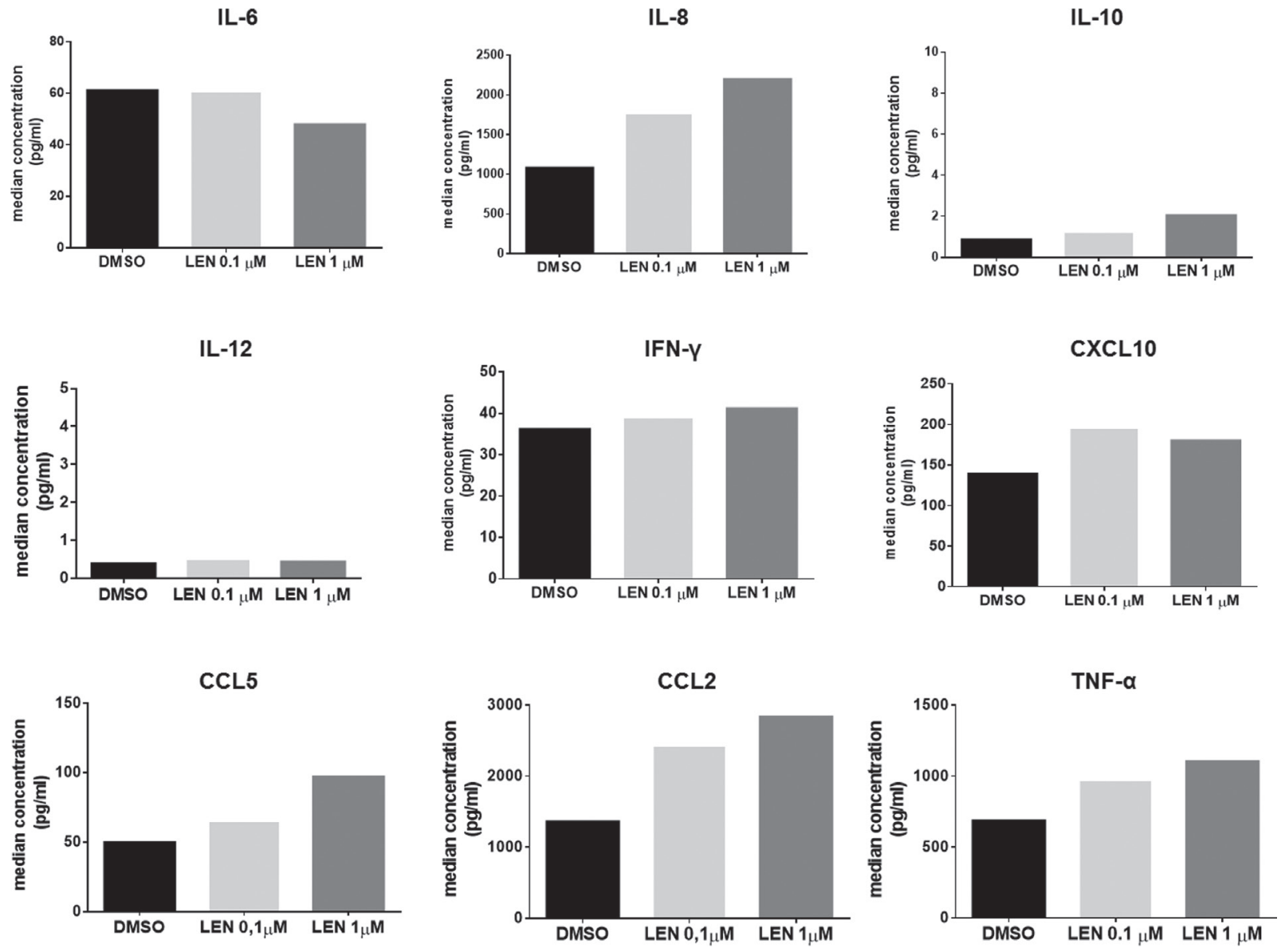

Figure 3: LEN increased the production of IL-8, CCL2, CCL5 and TNF- $\boldsymbol{\alpha}$ by DCs. DC CM was collected after in vitro DC differentiation from $\mathrm{BM} \mathrm{CD14}+$ cells of $5 \mathrm{MM}$ patients. The levels $(\mathrm{pg} / \mathrm{ml})$ of cytokines and chemokines involved in immune response were evaluated by a Bio-Plex ${ }^{\circledR}$ Multiplex System. Graph bars represent the median concentration of soluble factor levels in the presence of DMSO or LEN. For TNF- $\alpha$ level evaluation, the obtained results were normalized for TNF- $\alpha$ concentration measured in the control medium (RPMI 10\% FBS, with IL-4, GM-CSF and TNF- $\alpha$ at concentration used during DC differentiation). 
A

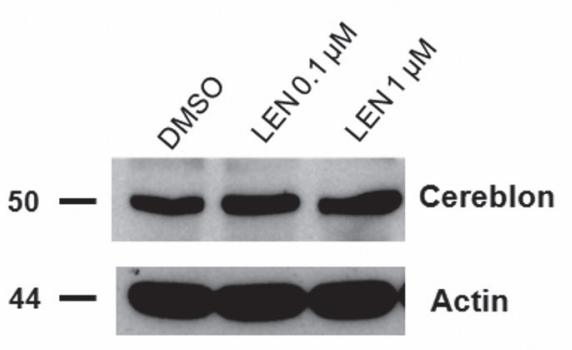

B

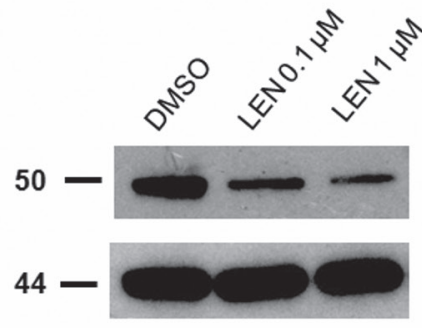

Ikaros

Actin

C

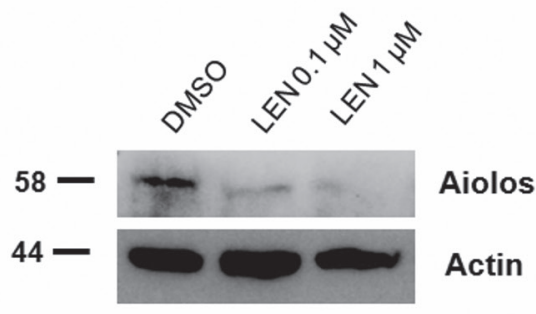

D

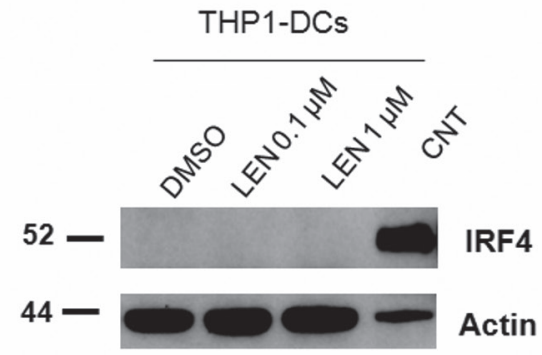

E

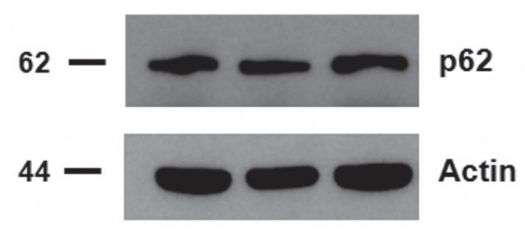

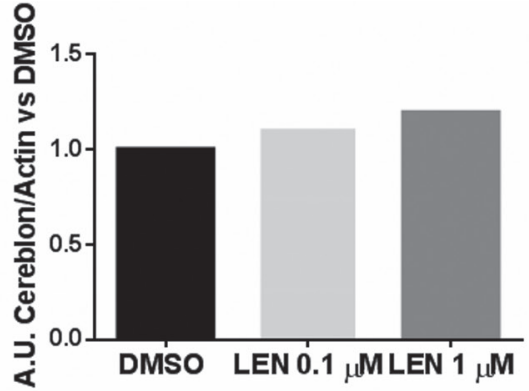
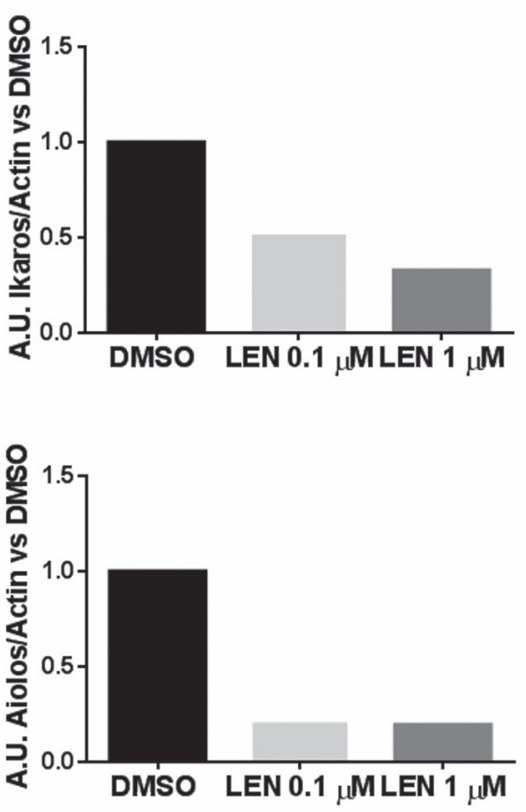

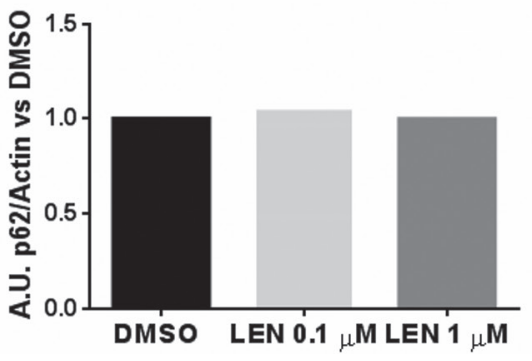

Figure 4: LEN effect on DC differentiation was mediated by Ikaros and Aiolos degradation. DCs were differentiated from THP-1 cell line, by adding rhIL-4 (200 ng/ml), rhGM-CSF $(100 \mathrm{ng} / \mathrm{ml})$, ionomycin $(200 \mathrm{ng} / \mathrm{ml})$ and rhTNF- $\alpha(20 \mathrm{ng} / \mathrm{ml})$ for $72 \mathrm{~h}$ to the culture medium (RPMI 1664, serum depleted); then LEN $(0.1$ and $1 \mu \mathrm{M})$ or DMSO were added for the last $24 \mathrm{~h}$ of culture period. Differentiated cells (THP1-DCs) were then collected and Cereblon (A), Ikaros (B), Aiolos (C), IRF4 (D) and p62 (E) protein levels were analyzed by Western Blotting. $\beta$-actin was used as internal control. 
CD80: $60.22 \pm 10.19$ vs $40.39 \pm 4.52$ vs $100.9 \pm 0.91$ CD209: $47.90 \pm 6.84$ vs $40.22 \pm 5.92$ vs $74.75 \pm 20.01$ ) (Supplementary Figure 3B).

\section{LEN treatment of MM patients increased ex vivo DC differentiation}

Finally, to evaluate the effect of in vivo LEN treatment on DC maturation markers, we compared the expression profile of DCs differentiated from PB CD14 cells of $9 \mathrm{MM}$ relapsed patients, purified at the baseline (DAY 0) and after 7 days of LEN treatment, just before the start of the weekly treatment with Dex. All the patients were responsive to LEN treatment.

Interestingly, we found that in vivo LEN treatment significantly increased the expression of HLA-DR (mean MFI \pm SEM: DAY 7 vs DAY 0, 80.59 \pm 11.21 vs $38.56 \pm 17.99, p=0.036)$ and CD209 (mean MFI \pm SEM: DAY 7 vs DAY 0, $194.24 \pm 30.22$ vs $116.47 \pm 23.47$, $p=0.012$ ), and CD86 without reaching statistical significance (mean MFI \pm SEM: DAY 7 vs DAY 0, $200.75 \pm 48.20 v s 107.95 \pm 19.21, p=0.075)(p$ calculated by paired Student's $t$-test) (Figure 8 ), as we showed for the in vitro treatment. The effect on CD209 expression was also observed after 21 days of LEN treatment (data not shown). Flow-cytometry histograms from one representative MM patient were reported in Supplementary Figure 4.

\section{DISCUSSION}

DCs of MM patients are known to be functionally defective, with a decreased expression of maturation markers and antigen presentation ability [19]. The production by $\mathrm{MM}$ cells of several soluble factors with immunosuppressive properties on DCs, such as IL-6, IL-10, vascular endothelial growth factor and TGF- $\beta$, contributes to these immunological defects [19, 30, 31]. LEN exerts its immunomodulatory activity through several mechanisms of action on T and NK cells; $[7,32]$ however, few literature data reported the effect of LEN on DCs in the contest of the anti-MM activity and in the increased incidence of GvHD observed in patients treated with this drug [33].

Studies performed on murine models, showed that both LEN and POM treatment increased the expression of DC maturation markers, enhanced DC endocytotic activity, increased the production of TNF- $\alpha$ and CCL2, and the DC-dependent T-cell expansion $[16,17]$. However, LEN effect on human DCs are still unclear. One study, recently published [18], reported that LEN $(5 \mu \mathrm{g} / \mathrm{ml} \approx$ $20 \mu \mathrm{M}$ ) enhanced the maturation of DCs generated from $\mathrm{PB}$ of MM patients and increased the ability to stimulate $\mathrm{T}$ cell proliferation in line with our results [18]. Particularly we found that LEN, at concentrations reached in vivo in MM patients treated with this drug 5-25 mg daily, [27, 34] significantly increased the expression of DC maturation markers, HLA-DR, CD86 and CD209, that are involved in DC co-stimulatory function and trafficking, [35-37] both in BM and PB of MM patients. This effect was abrogated in the presence of Dex at $10^{-8} \mathrm{M}$, consistent with several studies that reported Dex inhibitory effects on DC maturation and functions $[38,39]$. However, contradictory data were reported on the antagonistic effects of Dex on LEN immunomodulatory properties. A study from Paiva et al. [40] on high-risk Smoldering MM (SMM) patients reported no significant differences in the immune profile of patients treated with LEN/Dex vs LEN alone [40]. Conversely, different studies showed a profound inhibition
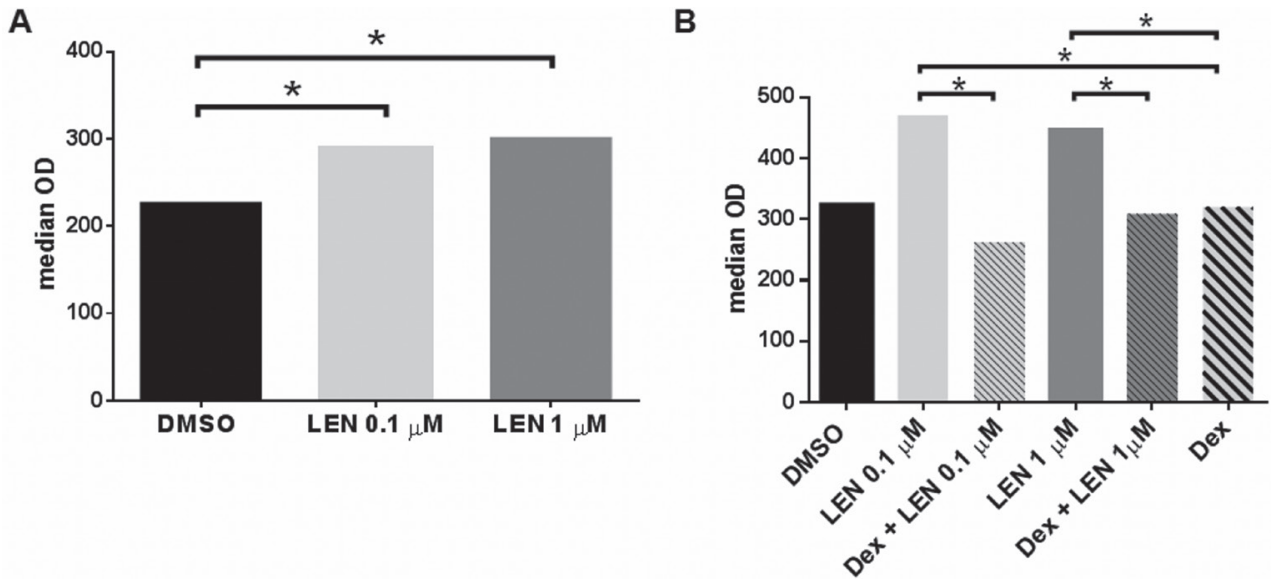

Figure 5: Effect of LEN on DC ability to stimulate T cell proliferation, alone and in combination with Dex. DCs were differentiated from BM CD14 ${ }^{+}$cells of 6 MM patients, in the presence of LEN or DMSO, alone (A) or in combination with Dex (B), as previously reported. At the end of culture period, cells were collected and reseeded $\left(3 \times 10^{3}\right.$ cells $\left./ \mathrm{w}\right)$ in round-bottomed $96 \mathrm{well}-\mathrm{plates}$, in RPMI 1640 with $15 \%$ AB human serum. DCs were co-cultured with autologous PB CD3 $3^{+}$cells $\left(1 \times 10^{4} / \mathrm{w}\right)$ for 6 days. At the end of culture period, an MTT assay was performed in order to measure T cell proliferation. Graph bars represent the median O.D. of T cell proliferation in co-culture with pre-treated DCs ( $p$ calculated by Mann-Whitney test ). 
A

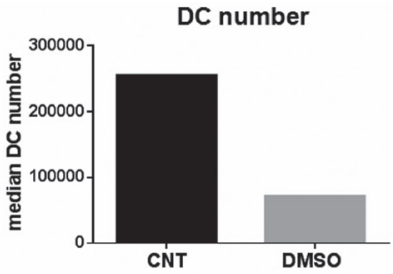

CD80

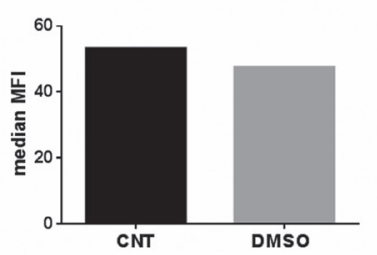

B

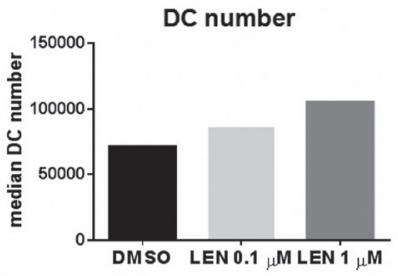

CD80

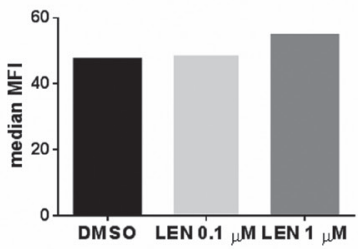

DC \%

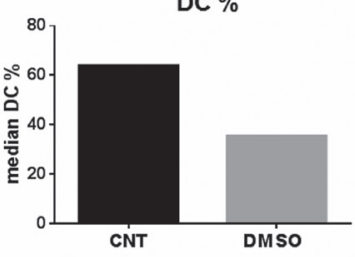

CD86
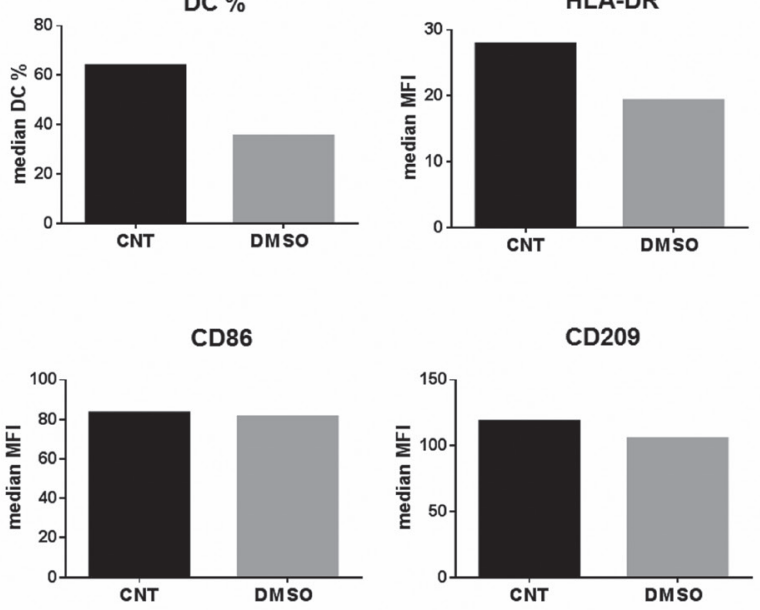

CD209
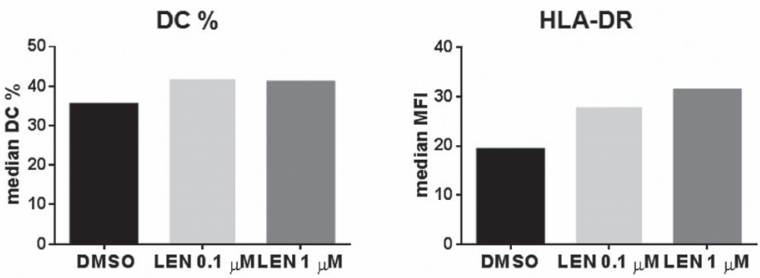

CD86
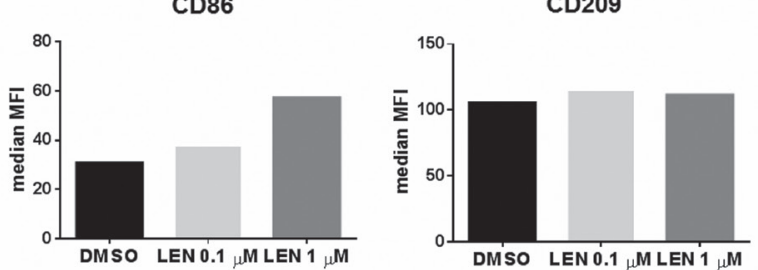

C

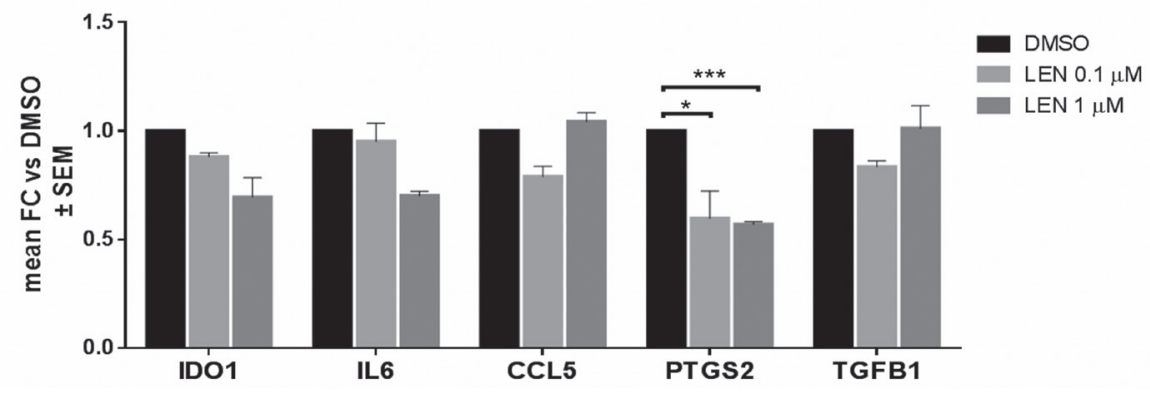

Figure 6: LEN blunted hTERT-hMSC inhibitory properties on DC differentiation through the down-regulation of PTGS2 expression levels. DCs were differentiated from BM CD14 cells of $3 \mathrm{MM}$ patients, in the presence or absence of the CM (ratio 1:2 with RPMI 1640 10\% FBS, with IL-4 and GM-CSF) of hTERT-hMSCs, treated with LEN (0.1 and $1 \mu \mathrm{M})$ or DMSO for 5 days. At the end of culture period, cells were collected and analyzed for DC maturation markers, by flow-cytometry. (A) The inhibitory effect of hTERT-hMSCs on in vitro DC differentiation was firstly checked. Graph bars represent the median of DC number and \% and MFI of DC maturation markers on DCs cultured with DMSO-treated hTERT-hMSCs CM or CNT (RPMI 10\% FBS). (B) The effect of LEN treated hTERT-hMSCs on DC differentiation was then evaluated. Graph bars represent the median of DC number and \% and MFI of DC maturation markers on DCs cultured with LEN-treated hTERT-hMSCs CM or DMSO. (C) hTERT-hMSCs were seeded in T75 flasks and cultured in RPMI $10 \%$ FBS, in presence of LEN $(0.1$ and $1 \mu \mathrm{M})$ or DMSO, for 5 days. At the end of culture period, cell pellets were collected and analyzed by RT-PCR for the mRNA expression of several immunosuppressive factors. Graph bars represent the mean Fold Change (FC) of LEN treated hTERT-hMSCs $v s$ DMSO \pm SEM of 3 independent experiments ( $p$ calculated by Student's $t$-test; ${ }^{*} p<0.05,{ }^{* * *} p<0.0001$ ). 
of LEN-mediated NK and T cell activation with Dex combination $[41,42]$.

Consistent with the effect of LEN on DC maturation markers, we found that LEN treatment increased DC production of IL-8, CCL2, CCL5, and $\mathrm{TNF}-\alpha$, in line with data observed on murine models $[16,17]$. These factors regulate the antigen uptake and the activation of the innate immune system, and are chemo-attractants for various immune cells, [43] suggesting that LEN treatment enhanced the role of DC in linking innate and adaptive anti-tumor-antigen immune responses. In line with this hypothesis, we showed that LEN effect on in vitro DC differentiation

A

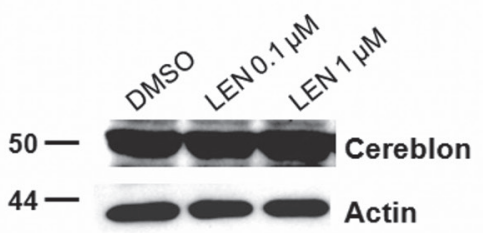

B

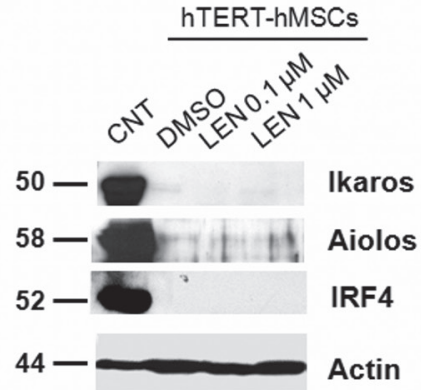

C

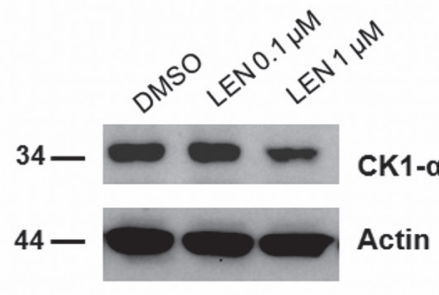

D

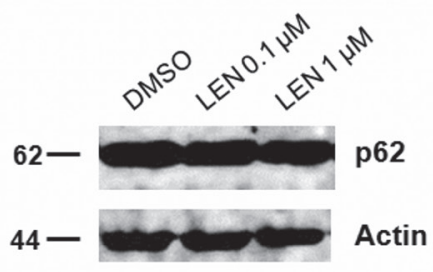

was associated with an increased DC functional activity to stimulate $\mathrm{T}$ cell proliferation that was abrogated by the combination with Dex.

Subsequently, we investigated the molecular mechanism beyond LEN effects on DCs. It is widely demonstrated that LEN exerts its anti-MM activity through the modulation of Ikaros and Aiolos [12, 13]. Moreover, Ikaros deficiency in host APCs failed to enhance GvLeukemia despite increased GvHD severity, in a murine model of allo-transplantation [44]. Similarly, we found that both Ikaros and Aiolos were degraded in DCs after LEN treatment, as previously showed for MM cells and T cells $[12,13][21]$.
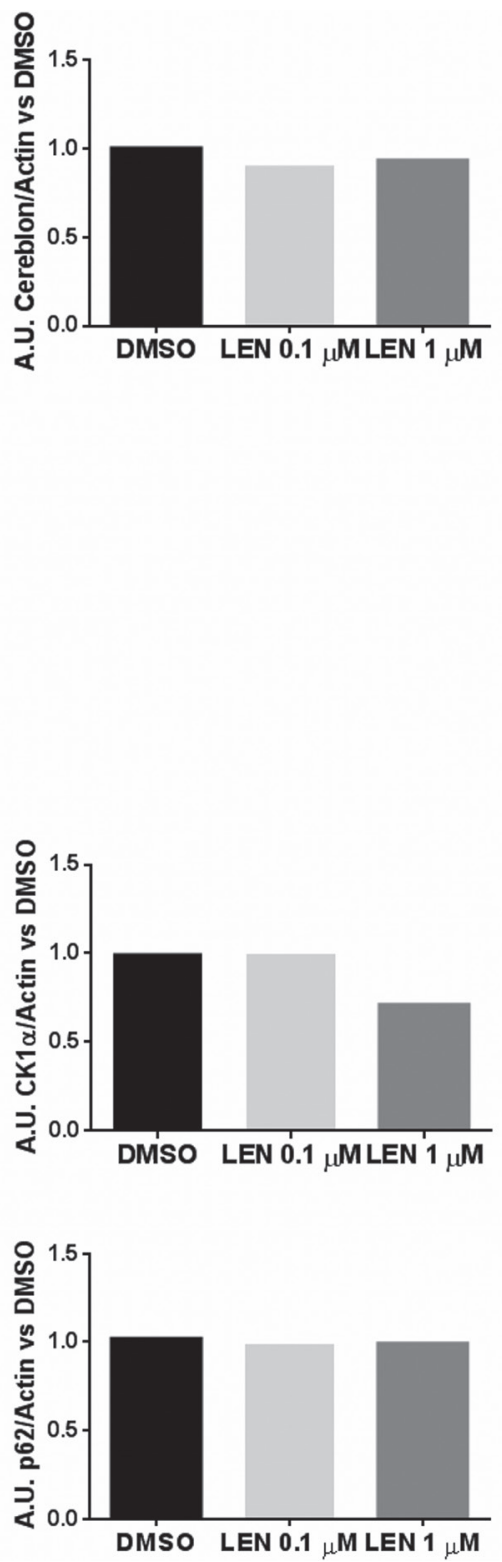

Figure 7: LEN treatment decreased CK1- $\alpha$ levels in hTERT-hMSCs. hTERT-hMSCs were seeded in T75 flasks and cultured in RPMI 10\% FBS, in presence of LEN $(0.1$ and $1 \mu \mathrm{M})$ or DMSO, for 5 days. At the end of culture period, cell pellets were collected and analyzed by Western Blotting for Cereblon (A), Ikaros (B), Aiolos (B), IRF4 (B), CK1- $\alpha$ (C) and p62 (D). $\beta$-actin was used as internal control. 
Along with a direct effect of LEN on DC maturation, our data suggested a potential indirect effect, through the modulation of MSC immunomodulatory properties such as the production of cytokines and chemokines. [24-26, 45] When DCs were cultured with LEN-treated MSC CM, we observed an increased expression of DC maturation markers suggesting the ability of LEN to blunt the inhibitory effect of MSCs on DC differentiation. Moreover, we found that the treatment of MSCs with LEN significantly decreased the expression levels of PTGS2, known to inhibit the transitional processes of differentiation of monocytes into DCs [46, 47]. The molecular mechanisms involved in the effect of LEN on MSC was also investigated. Surprisingly, we lacked to find the expression of the main Cereblon targets, Ikaros and Aiolos, by MSCs but we showed that LEN caused the degradation of a novel described Cereblon substrate, CK1 $1-\alpha$ in MSCs. CK1- $\alpha$ is a component of the beta $(\beta)$ catenin destruction complex and a negative regulator of p53, and several studies $[15,48]$ recently reported that reduced CK1- $\alpha$ levels decrease MM cell survival and inhibit cell cycle progression $[15,48]$. Interestingly, this factor seems to be involved in the resistance of plasma cells to LEN after long-term exposure [49].

Lastly, our in vitro evidences were expanded and confirmed by ex vivo DC cultures in relapsed MM patients treated with LEN $25 \mathrm{mg} /$ day, as mono-therapy for one week, just before the start of the weekly treatment with Dex. After 7 days of treatment we found an increased PB
DC differentiation. Of note, all analyzed patients were responsive to LEN treatment. This early effect was in agreement with recent data reporting the in vivo increase of T and NK cells, with a rapid decline of Ikaros, after 7 days of POM treatment without Dex in MM patients [50].

In conclusion, our data indicate that LEN increases the expression of mature DC markers both in vitro and in ex vivo cultures, enhancing $\mathrm{DC}$ ability to stimulate $\mathrm{T}$ cell proliferation and to release chemokines involved in the immune response. LEN treatment also reduces the immunosuppressive properties of hMSCs, suggesting new possible effects of IMiDs ${ }^{\circledR}$ on the allo-reactivity against MM cells.

\section{MATERIALS AND METHODS}

\section{Patients}

$\mathrm{BM}$ and/or PB were obtained from 30 consecutive patients with active MM (50\% female, $50 \%$ male; median age: 71 years, range 43-94), including both newly diagnosed and relapsed MM, admitted to our hematological Unit. Patient samples were obtained after informed consent, according to the Declaration of Helsinki. The study was approved by the Institutional Ethical Review Board of our Hospital.

Moreover, PB were obtained from 9 patients with relapsed MM (4 female, 5 male; median age: 73 years, range: 56-82; International Staging System (ISS) I: 4,
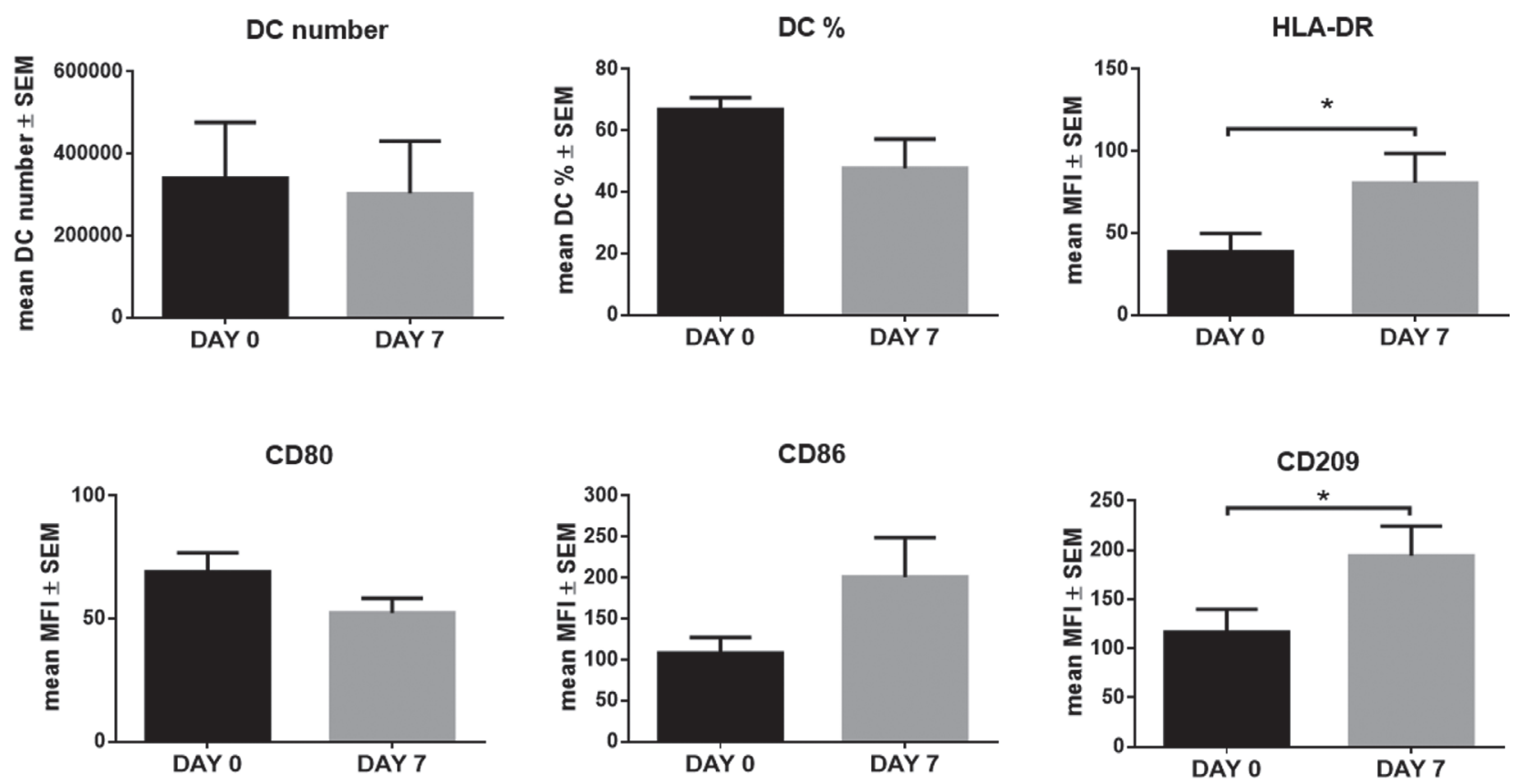

Figure 8: In vivo LEN treatment increased in vitro DC differentiation from CD14 cells of MM patients. DCs were in vitro differentiated from PB CD14+ cells of $9 \mathrm{MM}$ patients at DAY 0 and after one week (DAY 7) of LEN 25mg/day treatment. Cells were cultured in RPMI 10\% FBS with IL-4 and GM-CSF for 8 days and TNF- $\alpha$ was added for the last $24 \mathrm{~h}$. At the end of culture period, cells were collected and analyzed for DC maturation markers, by flow-cytometry. Graph bars represent the mean of DC number and \% and MFI of DC maturation markers at DAY $7 v s$ DAY $0 \pm$ SEM, of 9 independent experiments ( $p$ calculated by paired Student's $t$-test). 
International Staging System (ISS) II: 3, International Staging System (ISS) III: 2), at the baseline and after 7 days of treatment with LEN $25 \mathrm{mg}$ /day (days 1-21), just before the start of the weekly treatment with Dex.

Mononuclear cells (MNCs) were isolated from BM and PB samples after Ficoll gradient separation and used for further in vitro studies.

\section{Cells and cell culture conditions}

\section{Cell lines}

The human myeloma cell line (HMCL) JJN3, purchased by DSMZ (Braunschweig, Germany) and the human monocytic cell line THP-1, obtained from the American Type Culture Collection (Rockville, MD), were maintained in culture in RPMI 1640 medium with 10\% FBS; hTERT-hMSCs were kindly gifted from Dr Giuseppe Gaipa (Monza, Italy) and maintained in culture with RPMI $10 \%$ FBS with hydrocortisone $\left(10^{-6} \mathrm{M}\right)$. All cell lines were authenticated and tested for mycoplasma contamination.

\section{Cell purification}

$\mathrm{BM}$ and $\mathrm{PB} \mathrm{CD} 14^{+}$cells were purified from total MNCs by an immuno-magnetic method using antiCD14 mAb coated microbeads (MACS, Miltenyi Biotec; Bergisch-Gladbach, Germany). $\mathrm{CD}^{+}$cells were isolated following the same protocol, using anti-CD3 mAb from $\mathrm{PB}$ of MM patients. The presence of potential contaminating cells in each fraction was evaluated by flow cytometry analysis, using the fluorescence-activated flow cytometer BD FACS Canto II with Diva software (Becton, Dickinson and Company (BD); Franklin Lakes, NJ). Purity of cell samples was $>92 \%$.

\section{DC differentiation and cell treatment}

DCs were differentiated from purified CD $14^{+}$cells, cultured in vitro at $1 \times 10^{6}$ cells $/ \mathrm{ml}$ in RPMI $10 \% \mathrm{FBS}$, with recombinant human (rh) granulocyte macrophage colony-stimulating factor (GM-CSF) $(50 \mathrm{ng} / \mathrm{ml})$ and IL-4 (50 ng/ml) (all purchased by Peprotech, Rocky Hill, NJ), for 8 days (replacing half media with fresh cytokines every 2-3 days), in the presence of LEN (purchased by Celgene, Italy Corporation, Milan, Italy) or vehicle (DMSO), at concentration 0.1 and $1 \mu \mathrm{M}$. TNF- $\alpha$ at $10 \mathrm{ng} / \mathrm{ml}$ (OriGene; Rockville, MD) was added to the culture medium for the last $24 \mathrm{~h}$, in order to induce DC terminal maturation. At the end of culture period, both cells and CM were collected for further analysis. In some experiment, the combination of LEN and Dex (obtained by Sigma Aldrich, Milan, Italy) was tested on DC differentiation. Briefly, DCs were differentiated from $\mathrm{BM} \mathrm{CD} 14^{+}$cells of MM patients, in the presence of $\operatorname{LEN}(0.1$ and $1 \mu \mathrm{M})$ or vehicle, as reported above. At the end of culture period, cells were collected and reseeded $\left(5 \times 10^{4} / \mathrm{ml}\right)$ in fresh medium with Dex $\left(10^{-8} \mathrm{M}\right)$ or vehicle $(\mathrm{EtOH})$ for $48 \mathrm{~h}$. After Dex treatment, cells were collected and analyzed for DC maturation markers.

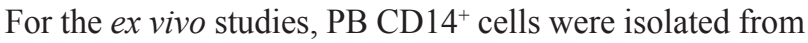
MM patients at day 0 and after one week (day 7) of LEN (25 mg/day) treatment, just before the start of the weekly treatment with Dex. Cells were then differentiated into DCs, following the above protocol, without LEN in vitro treatment.

DCs were also differentiated from THP-1 cell line, by adding rhIL-4 (200 ng/ml), rhGM-CSF (100 ng/ml), ionomycin (200 ng/ml) (Sigma-Aldrich, Milan, Italy) and rhTNF- $\alpha(20 \mathrm{ng} / \mathrm{ml})$ for $72 \mathrm{~h}$ to the culture medium (RPMI 1640 , serum depleted); then LEN or DMSO were added for the last $24 \mathrm{~h}$ of culture period. THP-1-derived DCs (THP1-DCs) were detached with EDTA $2 \mathrm{mM}$ on ice for $2 \mathrm{~h}$ and cell pellets collected for further analysis.

In some experiments DCs were differentiated from $\mathrm{BM} \mathrm{CD14}{ }^{+}$cells of $\mathrm{MM}$ patients, in the presence or absence of the CM (ratio 1:2 with RPMI 10\% FBS, with IL-4 and GM-CSF) of hTERT-hMSCs treated with LEN or DMSO. Briefly, $1 \times 10^{4}$ hTERT-hMSCs were seeded in T75 flasks and cultured in RPMI 10\% FBS, in presence of $\operatorname{LEN}(0.1$ and $1 \mu \mathrm{M})$ or DMSO, for 5 days. At the end of culture period, the medium was replaced with RPMI $10 \%$ FBS in order to discard LEN, and after $48 \mathrm{~h}$, the $\mathrm{CM}$ was collected and used during DC differentiation, as previously reported. In some experiments, after 5 days of LEN treatment, hTERT-hMSC pellets were collected for immunoblotting and RT-PCR analysis.

\section{Autologous mixed lymphocyte reaction and cell proliferation assay}

DCs were differentiated, as previously reported, in presence of LEN or vehicle (alone or in combination with Dex), from BM of 6 MM patients, for 8 days. Then, treated cells were collected, analyzed by flow-cytometry and partly re-seeded $\left(3 \times 10^{3}\right.$ cells $\left./ \mathrm{w}\right)$ in round-bottomed 96well-plates, in RPMI 15\% AB human serum. DCs were co-cultured with autologous $\mathrm{PB} \mathrm{CD} 3^{+}$cells $\left(1 \times 10^{4}\right)$ for 6 days. At the end of culture period, an MTT assay (Cell Counting Kit-8; Alexis, Vinci-Biochem s.r.l., Italy) was performed in order to measure $\mathrm{T}$ cell proliferation.

\section{Flow cytometry assay}

After in vitro DC differentiation, non-adherent cells were collected and analyzed by flow cytometry for DC maturation markers. Cells from each condition were splitted in three tubes and labelled with saturating amounts of the following conjugated antibody combinations (all from BD Biosciences, San Jose, CA, USA): 1) anti-CD14-FITC/antiCD83-PE/isotype control-PE-Cy5/isotype control-APC, 2) anti-CD14-FITC/anti-CD83-PE/anti-CD86-PE-Cy5/antiHLA-DR-APC, 3) anti-CD14-FITC/anti-CD83-PE/antiCD80-PE-Cy5/anti-CD209-APC. Four color, six-parameter acquisition and analysis were perfomed on a two-laser FACSCalibur instrument (BD Biosciences) using CellQuest software (BD Biosciences). Mature DCs were identified as 
$\mathrm{CD} 14^{-} \mathrm{CD} 83^{+}$cells and the MFI of the maturation markers was compared between cells treated with LEN and/or Dex vs the relative control, for each experiment.

\section{Multi ELISA assay}

The concentration of Interferon (IFN)- $\gamma$, IL-6, IL-8, IL-10, IL-12, IFN- $\gamma$ induced protein (IP)-10, CCL2, CCL5 and TNF- $\alpha$ was evaluated on DC CM, collected after in vitro $\mathrm{DC}$ differentiation, by using multiplex bead-based sandwich immunoassay kits (Bio-Plex ${ }^{\circledR}$ Multiplex System, Biorad, California, USA), following the manufacturer's instructions. Measurement were performed by a reader (Luminex Bio-plex system, Bio-Rad Laboratories Inc.). For TNF- $\alpha$ level evaluation, the obtained results were normalized for TNF- $\alpha$ concentration measured in the control medium (RPMI 10\% FBS, with IL-4, GM-CSF and TNF- $\alpha$ at concentrations used during DC differentiation).

\section{Western blotting}

Nuclear and cytosolic extracts were obtained using a commercial kit (Active Motif, Carlsbad, CA) following the manufacturer's protocol from THP1-DCs and hTERThMSCs, treated with LEN or DMSO. Immunoblotting was performed as previously reported [51] using the following antibodies: rabbit monoclonal anti-Aiolos (1:714) (code $n$. NBP2-24495, Novus Biologicals, Abingdon, UK), antiCasein Kinase 1 (1:1.000) (code n. 2655, Cell Signaling Technology, Danvers, USA), anti-Ikaros (1:200) (code n. sc-13039, Santa Cruz Biotechnology, Dallas, USA), and mouse monoclonal anti-Cereblon (1:1.250) (code n.TA345038, OriGene, Rockville, USA), anti-IRF4 (1:400) (code n. M725929-2, DAKO, Milan, Italy); anti-p62/ SQSTM1 (1:250) (Code n.MAB8028, R\&D Systems, Minneapolis, MN, USA) antibodies; mouse monoclonal anti- $\beta$-actin antibody (1:5.000) (clone AC-15, code n. A5441, Sigma-Aldrich, Milan, Italy) was used as internal control. JJN3 cell line represents the positive control (CNT).

\section{mRNA silencing}

RNAi was performed through the generation of inducible shRNA stable cell lines. hTERT-hMSC were transduced with the IPTG inducible lentiviral particles carrying CSNK1A1-specific shRNA (pLKO_ IPTG_3XLacO, Sigma-Aldrich, Milan, Italy). Two independent shRNAs (TRCN0000006044, and TRCN0000006042) sequences were chosen. $3 \times 10^{4}$ cells were infected with a multiplicity of infection (MOI) of 4 , in the presence of $8 \mu \mathrm{g} / \mathrm{ml}$ polybrene (Sigma-Aldrich, Milan, Italy). $24 \mathrm{~h}$ later, the infected medium was replaced with fresh growing medium. Puromycin selection $(0.5 \mu \mathrm{g} / \mathrm{ml})$ was initiated 2 days after transduction. Once a cellular clone was established, to induce $\mathrm{CK} 1 \alpha$ silencing, cells were incubated with $500 \mu \mathrm{M}$ IPTG (Sigma-Aldrich,
Milan, Italy) every 2-3 days for a total of one week. Then, fresh medium without IPTG and puromycin was added for further $48 \mathrm{~h}$. At the end of culture period, cell pellets were collected and analyzed by western blotting to check CK1- $\alpha$ down-regulation and select the more efficient clone. CM was also collected and used for in vitro DC differentiation.

\section{RT-PCR}

Total RNA was extracted from hTERT-hMSCs, after all different experimental conditions, using the RNeasy total RNA isolation kit (Qiagen; Hilden, Germany). RNA (1 $\mu \mathrm{g})$ was reverse-transcribed with $400 \mathrm{U}$ Moloney murine leukemia reverse transcriptase (Applied Biosystems, Life Technologies, Carlsbad, CA, USA) in accordance with the manufacturer's protocol. Real Time PCR was performed by adding complementary DNA to a universal Light Cycler 480 Probes Master and RealTime ready Catalog Assay (Roche Diagnostics, Mannheim, Germany) for the following genes: IDO1 (Assay ID:103804), IL6 (Assay ID: 144013), CCL5 (Assay ID: 113395), PTGS2 (Assay ID: 102471), TGB1 (Assay ID: 101210), and GAPDH (Assay ID: 102052). The expression of selected genes was checked by Real Time PCR by Light Cycler 480 (Roche Diagnostics, Mannheim, Germany). To normalize the differences in RNA quality and reverse transcription efficiency, we applied the comparative $\mathrm{Ct}$ method using the endogenous reference gene GAPDH.

\section{Statistical analysis}

Data were expressed as mean \pm SEM or median values. Paired Student's $t$-test was used to analyze flow cytometry data of in vitro DC differentiation from BM and $\mathrm{PB}$ of MM patients and for the ex vivo studies. Nonparametric Friedman test, Wilcoxon test and MannWhitney test were used for the other experiments with a lower number of samples. Results were considered significant at $p<0.05$. GraphPad Prism 6.1 ${ }^{\text {TM }}$ (GraphPad Software Inc., La Jolla, CA, USA) was used for all the statistical analyses.

\section{Abbreviations}

IMiDs $^{\circledR}$ : Immunomodulatory drugs; LEN: Lenalidomide; POM: Pomalidomide; MM: Multiple myeloma; T reg: T regulatory cell; ADCC: Antibodydependent cell-mediated citotoxicity; NK: Natural killer; CRBN: Cereblon; CRL: Cullin-RING E3 ubiquitin ligase; CK1- $\alpha$ : Casein kinase 1 alpha; IL: interleukin; MDS: myelodysplastic; del(5q): deletion of chromosome 5q; DCs: dendritic cells; PB: peripheral blood; aGvHD: acute graft versus host disease; MSCs: mesenchymal stromal cells; APCs: antigen presenting cells; Mo-DCs: monocytes derived dendritic cells; BM: bone marrow; SEM: standard 
error of the mean; Dex: Dexamethasone; CCL: CC chemokine ligand; TNF- $\alpha$ : tumor necrosis factor alpha; MLR: Mixed Lymphocyte Reaction; hTERT-hMSCs: human telomerase reverse transcriptase transduced mesenchymal stromal cells; CM: conditioned medium; RTPCR: Real Time PCR; PTGS2: prostaglandine 2; IDO1: indoleamine 2,3-dioxygenase1; TGFB1: Transforming growth factor beta 1; SMM: Smoldering MM; MNCs: Mononuclear cells; rh: recombinant human; GM-CSF: granulocyte macrophage colony-stimulating factor; HMCL: Human myeloma cell line; mAb: Monoclonal antibody; ISS: International staging system; IFN- $\gamma$ : Interferon gamma; THP1-DCs: THP-1 derived DCs; IP10: IFN- $\gamma$ induced protein 10.

\section{Authors' contributions}

F.C., M.B. and D.T. collected samples and performed experiments. R.V. performed the flow cytometry analysis. V.M. and P.S. performed Real-time PCR. C.M. performed Multi ELISA assay and G.L. analyzed results. S.M. performed mRNA silencing. G.T. performed cytogenetic analysis. F.A., L.N., B.D.P. and N.G. provided clinical data and patients. N.G. designed the research, N.G. analyzed results, F.C. and N.G. wrote the paper. F.C., F.P. and F.A. read, provided comments, and approved the final version of the manuscript.

\section{ACKNOWLEDGMENTS}

The authors would like to thank Francesco F Fagnoni for his critical reading of the manuscript and Dirce Gennari for her technical support.

\section{CONFLICTS OF INTEREST}

N.G. received a research grant from Celgene Italy and Janssen Pharmaceutical.

\section{FUNDING}

This work was supported in part by a grant from Celgene (N.G.) and a grant from the Associazione Italiana per la Ricerca sul Cancro (AIRC) IG2014 n.15531 (N.G.), two fellowships Fondazione Italiana per la Ricerca sul Cancro ID 16462 (D.T.) and ID 18152 (M.B.), a fellowship from ParmAIL (V.M.).

\section{REFERENCES}

1. Kumar SK, Rajkumar SV, Dispenzieri A, Lacy MQ, Hayman SR, Buadi FK, Zeldenrust SR, Dingli D, Russell SJ, Lust JA, Greipp PR, Kyle RA, Gertz MA. Improved survival in multiple myeloma and the impact of novel therapies. Blood. 2008; 111:2516-20. doi: 10.1182/ blood-2007-10-116129.
2. Raje N, Hideshima T, Anderson KC. Therapeutic use of immunomodulatory drugs in the treatment of multiple myeloma. Expert Rev Anticancer Ther. 2006; 6:1239-47. doi: 10.1586/14737140.6.9.1239.

3. Dimopoulos M, Spencer A, Attal M, Prince HM, Harousseau JL, Dmoszynska A, San Miguel J, Hellmann A, Facon T, Foa R, Corso A, Masliak Z, Olesnyckyj M, et al. Lenalidomide plus dexamethasone for relapsed or refractory multiple myeloma. N Engl J Med. 2007; 357:2123-32. doi: 10.1056/NEJMoa070594.

4. Weber DM, Chen C, Niesvizky R, Wang M, Belch A, Stadtmauer EA, Siegel D, Borrello I, Rajkumar SV, ChananKhan AA, Lonial S, Yu Z, Patin J, et al. Lenalidomide plus dexamethasone for relapsed multiple myeloma in North America. N Engl J Med. 2007; 357:2133-42. doi: 10.1056/ NEJMoa070596.

5. Benboubker L, Dimopoulos MA, Dispenzieri A, Catalano J, Belch AR, Cavo M, Pinto A, Weisel K, Ludwig H, Bahlis N, Banos A, Tiab M, Delforge M, et al. Lenalidomide and dexamethasone in transplant-ineligible patients with myeloma. N Engl J Med. 2014; 371:906-17. doi: 10.1056/ NEJMoa1402551.

6. Palumbo A, Cavallo F, Gay F, Di Raimondo F, Ben Yehuda D, Petrucci MT, Pezzatti S, Caravita T, Cerrato C, Ribakovsky E, Genuardi M, Cafro A, Marcatti M, et al. Autologous transplantation and maintenance therapy in multiple myeloma. N Engl J Med. 2014; 371:895-905. doi: 10.1056/NEJMoa1402888.

7. Sedlarikova L, Kubiczkova L, Sevcikova S, Hajek R. Mechanism of immunomodulatory drugs in multiple myeloma. Leuk Res. 2012; 36:1218-24. doi: 10.1016/j. leukres.2012.05.010.

8. Bolzoni M, Storti P, Bonomini S, Todoerti K, Guasco D, Toscani D, Agnelli L, Neri A, Rizzoli V, Giuliani N. Immunomodulatory drugs lenalidomide and pomalidomide inhibit multiple myeloma-induced osteoclast formation and the RANKL/OPG ratio in the myeloma microenvironment targeting the expression of adhesion molecules. Exp Hematol. 2013; 41:387-97 e1. doi: 10.1016/j.exphem.2012.11.005.

9. Luptakova K, Rosenblatt J, Glotzbecker B, Mills H, Stroopinsky D, Kufe T, Vasir B, Arnason J, Tzachanis D, Zwicker JI, Joyce RM, Levine JD, Anderson KC, et al. Lenalidomide enhances anti-myeloma cellular immunity. Cancer Immunol Immunother. 2013; 62:39-49. doi: 10.1007/s00262-012-1308-3.

10. Zhu YX, Braggio E, Shi CX, Bruins LA, Schmidt JE, Van Wier S, Chang XB, Bjorklund CC, Fonseca R, Bergsagel PL, Orlowski RZ, Stewart AK. Cereblon expression is required for the antimyeloma activity of lenalidomide and pomalidomide. Blood. 2011; 118:4771-9. doi: 10.1182/ blood-2011-05-356063.

11. Schuster SR, Kortuem KM, Zhu YX, Braggio E, Shi CX, Bruins LA, Schmidt JE, Ahmann G, Kumar S, Rajkumar SV, Mikhael J, Laplant B, Champion MD, et al. The clinical significance of cereblon expression in multiple myeloma. Leuk Res. 2014; 38:23-8. doi: 10.1016/j.leukres.2013.08.015. 
12. Kronke J, Udeshi ND, Narla A, Grauman P, Hurst SN, McConkey M, Svinkina T, Heckl D, Comer E, Li X, Ciarlo C, Hartman E, Munshi N, et al. Lenalidomide causes selective degradation of IKZF1 and IKZF3 in multiple myeloma cells. Science. 2014; 343:301-5. doi: 10.1126/science.1244851.

13. Lu G, Middleton RE, Sun H, Naniong M, Ott CJ, Mitsiades CS, Wong KK, Bradner JE, Kaelin WG Jr. The myeloma drug lenalidomide promotes the cereblondependent destruction of Ikaros proteins. Science. 2014; 343:305-9. doi: 10.1126/science.1244917.

14. Kronke J, Fink EC, Hollenbach PW, MacBeth KJ, Hurst SN, Udeshi ND, Chamberlain PP, Mani DR, Man HW, Gandhi AK, Svinkina T, Schneider RK, McConkey M, et al. Lenalidomide induces ubiquitination and degradation of CK1alpha in del(5q) MDS. Nature. 2015; 523:183-8. doi: 10.1038/nature14610.

15. Manni S, Carrino M, Manzoni M, Gianesin K, Nunes SC, Costacurta M, Tubi LQ, Macaccaro P, Taiana E, Cabrelle A, Barila G, Martines A, Zambello R, et al. Inactivation of CK1alpha in multiple myeloma empowers drug cytotoxicity by affecting AKT and beta-catenin survival signaling pathways. Oncotarget. 2017; 8:14604-19. doi: 10.18632/oncotarget.14654.

16. Reddy N, Hernandez-Ilizaliturri FJ, Deeb G, Roth M, Vaughn M, Knight J, Wallace P, Czuczman MS. Immunomodulatory drugs stimulate natural killer-cell function, alter cytokine production by dendritic cells, and inhibit angiogenesis enhancing the anti-tumour activity of rituximab in vivo. Br J Haematol. 2008; 140:36-45. doi: 10.1111/j.1365-2141.2007.06841.x.

17. Henry JY, Labarthe MC, Meyer B, Dasgupta P, Dalgleish AG, Galustian C. Enhanced cross-priming of naive CD8+ T cells by dendritic cells treated by the $\mathrm{IMiDs}(\mathrm{R})$ immunomodulatory compounds lenalidomide and pomalidomide. Immunology. 2013; 139:377-85. doi: 10.1111/imm.12087.

18. Vo MC, Anh-NguyenThi T, Lee HJ, Nguyen-Pham TN, Jaya Lakshmi T, Jung SH, Kim HJ, Lee JJ. Lenalidomide enhances the function of dendritic cells generated from patients with multiple myeloma. Exp Hematol. 2017; 46:48-55. doi: 10.1016/j.exphem.2016.11.004.

19. Ratta M, Fagnoni F, Curti A, Vescovini R, Sansoni P, Oliviero B, Fogli M, Ferri E, Della Cuna GR, Tura S, Baccarani M, Lemoli RM. Dendritic cells are functionally defective in multiple myeloma: the role of interleukin-6. Blood. 2002; 100:230-7.

20. Romano A, Conticello C, Cavalli M, Vetro C, La Fauci A, Parrinello NL, Di Raimondo F. Immunological dysregulation in multiple myeloma microenvironment. Biomed Res Int. 2014; 2014:198539. doi: 10.1155/2014/198539.

21. Alsina M, Becker PS, Zhong X, Adams A, Hari P, Rowley S, Stadtmauer EA, Vesole DH, Logan B, Weisdorf D, Qazilbash M, Popplewell LL, McClune B, et al. Lenalidomide maintenance for high-risk multiple myeloma after allogeneic hematopoietic cell transplantation. Biol Blood Marrow Transplant. 2014; 20:1183-9. doi: 10.1016/j. bbmt.2014.04.014.
22. Coman T, Bachy E, Michallet M, Socie G, Uzunov M, Bourhis JH, Lapusan S, Brebion A, Vigouroux S, Maury S, Francois S, Huynh A, Lioure B, et al. Lenalidomide as salvage treatment for multiple myeloma relapsing after allogeneic hematopoietic stem cell transplantation: a report from the French Society of Bone Marrow and Cellular Therapy. Haematologica. 2013; 98:776-83. doi: 10.3324/ haematol.2012.069328.

23. Kneppers E, van der Holt B, Kersten MJ, Zweegman S, Meijer E, Huls G, Cornelissen JJ, Janssen JJ, Huisman C, Cornelisse PB, Bruijnen CP, Emmelot M, Sonneveld P, et al. Lenalidomide maintenance after nonmyeloablative allogeneic stem cell transplantation in multiple myeloma is not feasible: results of the HOVON 76 Trial. Blood. 2011; 118:2413-9. doi: 10.1182/blood-2011-04-348292.

24. Le Blanc K, Ringden O. Immunobiology of human mesenchymal stem cells and future use in hematopoietic stem cell transplantation. Biol Blood Marrow Transplant. 2005; 11:321-34. doi: 10.1016/j.bbmt.2005.01.005.

25. Nauta AJ, Fibbe WE. Immunomodulatory properties of mesenchymal stromal cells. Blood. 2007; 110:3499-506. doi: 10.1182/blood-2007-02-069716.

26. Chen X, Armstrong MA, Li G. Mesenchymal stem cells in immunoregulation. Immunol Cell Biol. 2006; 84:413-21. doi: 10.1111/j.1440-1711.2006.01458.x.

27. Richardson PG, Schlossman RL, Weller E, Hideshima T, Mitsiades C, Davies F, LeBlanc R, Catley LP, Doss D, Kelly K, McKenney M, Mechlowicz J, Freeman A, et al. Immunomodulatory drug CC-5013 overcomes drug resistance and is well tolerated in patients with relapsed multiple myeloma. Blood. 2002; 100:3063-7. doi: 10.1182/ blood-2002-03-0996.

28. Lopez-Girona A, Heintel D, Zhang LH, Mendy D, Gaidarova S, Brady H, Bartlett JB, Schafer PH, Schreder M, Bolomsky A, Hilgarth B, Zojer N, Gisslinger H, et al. Lenalidomide downregulates the cell survival factor, interferon regulatory factor-4, providing a potential mechanistic link for predicting response. Br J Haematol. 2011; 154:325-36. doi: 10.1111/j.1365-2141.2011.08689.x.

29. Zhu YX, Braggio E, Shi CX, Kortuem KM, Bruins LA, Schmidt JE, Chang XB, Langlais P, Luo M, Jedlowski P, LaPlant B, Laumann K, Fonseca R, et al. Identification of cereblon-binding proteins and relationship with response and survival after IMiDs in multiple myeloma. Blood. 2014; 124:536-45. doi: 10.1182/blood-2014-02-557819.

30. Brown RD, Pope B, Murray A, Esdale W, Sze DM, Gibson J, Ho PJ, Hart D, Joshua D. Dendritic cells from patients with myeloma are numerically normal but functionally defective as they fail to up-regulate CD80 (B7-1) expression after huCD40LT stimulation because of inhibition by transforming growth factor-betal and interleukin-10. Blood. 2001; 98:2992-8.

31. Leone P, Berardi S, Frassanito MA, Ria R, De Re V, Cicco S, Battaglia S, Ditonno P, Dammacco F, Vacca A, Racanelli V. Dendritic cells accumulate in the bone marrow 
of myeloma patients where they protect tumor plasma cells from CD8+ T-cell killing. Blood. 2015; 126:1443-51. doi: 10.1182/blood-2015-01-623975.

32. Quach H, Ritchie D, Stewart AK, Neeson P, Harrison S, Smyth MJ, Prince HM. Mechanism of action of immunomodulatory drugs (IMiDS) in multiple myeloma. Leukemia. 2010; 24:2232. doi: 10.1038/leu.2009.236.

33. Wolschke C, Stubig T, Hegenbart U, Schonland S, Heinzelmann M, Hildebrandt Y, Ayuk F, Atanackovic D, Dreger P, Zander A, Kroger N. Postallograft lenalidomide induces strong NK cell-mediated antimyeloma activity and risk for T cell-mediated GvHD: Results from a phase I/II dose-finding study. Exp Hematol. 2013; 41:134-42.e3. doi: 10.1016/j.exphem.2012.10.004.

34. Chen N, Wen L, Lau H, Surapaneni S, Kumar G. Pharmacokinetics, metabolism and excretion of [(14)C]lenalidomide following oral administration in healthy male subjects. Cancer Chemother Pharmacol. 2012; 69:789-97. doi: 10.1007/s00280-011-1760-3.

35. Geijtenbeek TB, Krooshoop DJ, Bleijs DA, van Vliet SJ, van Duijnhoven GC, Grabovsky V, Alon R, Figdor CG, van Kooyk Y. DC-SIGN-ICAM-2 interaction mediates dendritic cell trafficking. Nat Immunol. 2000; 1:353-7. doi: 10.1038/79815.

36. Geijtenbeek TB, Torensma R, van Vliet SJ, van Duijnhoven GC, Adema GJ, van Kooyk Y, Figdor CG. Identification of DC-SIGN, a novel dendritic cell-specific ICAM-3 receptor that supports primary immune responses. Cell. 2000; 100:575-85.

37. Banchereau J, Briere F, Caux C, Davoust J, Lebecque S, Liu YJ, Pulendran B, Palucka K. Immunobiology of dendritic cells. Annu Rev Immunol. 2000; 18:767-811. doi: 10.1146/annurev.immunol.18.1.767.

38. Piemonti L, Monti P, Allavena P, Sironi M, Soldini L, Leone BE, Socci C, Di Carlo V. Glucocorticoids affect human dendritic cell differentiation and maturation. J Immunol. 1999; 162:6473-81.

39. Matasic R, Dietz AB, Vuk-Pavlovic S. Dexamethasone inhibits dendritic cell maturation by redirecting differentiation of a subset of cells. J Leukoc Biol. 1999; 66:909-14.

40. Paiva B, Mateos MV, Sanchez-Abarca LI, Puig N, Vidriales MB, Lopez-Corral L, Corchete LA, Hernandez MT, Bargay J, de Arriba F, de la Rubia J, Teruel AI, Giraldo P, et al. Immune status of high-risk smoldering multiple myeloma patients and its therapeutic modulation under LenDex: a longitudinal analysis. Blood. 2016; 127:1151-62. doi: 10.1182/blood-2015-10-662320.

41. Hsu AK, Quach H, Tai T, Prince HM, Harrison SJ, Trapani JA, Smyth MJ, Neeson P, Ritchie DS. The immunostimulatory effect of lenalidomide on NK-cell function is profoundly inhibited by concurrent dexamethasone therapy. Blood. 2011; 117:1605-13. doi: 10.1182/blood-2010-04-278432.
42. Gandhi AK, Kang J, Capone L, Parton A, Wu L, Zhang LH, Mendy D, Lopez-Girona A, Tran T, Sapinoso L, Fang W, Xu S, Hampton G, et al. Dexamethasone synergizes with lenalidomide to inhibit multiple myeloma tumor growth, but reduces lenalidomide-induced immunomodulation of $\mathrm{T}$ and NK cell function. Curr Cancer Drug Targets. 2010; 10:155-67.

43. Nagorsen D, Marincola FM, Panelli MC. Cytokine and chemokine expression profiles of maturing dendritic cells using multiprotein platform arrays. Cytokine. 2004; 25:31-5.

44. Toubai T, Guoqing H, Rossi C, Mathewson N, OraveczWilson K, Cummings E, Wu J, Sun Y, Choi S, Reddy P. Ikaros deficiency in host hematopoietic cells separates GVL from GVHD after experimental allogeneic hematopoietic cell transplantation. Oncoimmunology. 2015; 4:e1016699. doi: 10.1080/2162402x.2015.1016699.

45. Kyurkchiev D, Bochev I, Ivanova-Todorova E, Mourdjeva M, Oreshkova T, Belemezova K, Kyurkchiev S. Secretion of immunoregulatory cytokines by mesenchymal stem cells. World J Stem Cells. 2014; 6:552-70. doi: 10.4252/wjsc.v6.i5.552.

46. Spaggiari GM, Abdelrazik H, Becchetti F, Moretta L. MSCs inhibit monocyte-derived DC maturation and function by selectively interfering with the generation of immature DCs: central role of MSC-derived prostaglandin E2. Blood. 2009; 113:6576-83. doi: 10.1182/blood-2009-02-203943.

47. Chen K, Wang D, Du WT, Han ZB, Ren H, Chi Y, Yang SG, Zhu D, Bayard F, Han ZC. Human umbilical cord mesenchymal stem cells hUC-MSCs exert immunosuppressive activities through a PGE2-dependent mechanism. Clin Immunol. 2010; 135:448-58. doi: 10.1016/j.clim.2010.01.015.

48. Hu Y, Song W, Cirstea D, Lu D, Munshi NC, Anderson KC. CSNK1alphal mediates malignant plasma cell survival. Leukemia. 2015; 29:474-82. doi: 10.1038/leu.2014.202.

49. Bjorklund CC, Ma W, Wang ZQ, Davis RE, Kuhn DJ, Kornblau SM, Wang M, Shah JJ, Orlowski RZ. Evidence of a role for activation of Wnt/beta-catenin signaling in the resistance of plasma cells to lenalidomide. J Biol Chem. 2011; 286:11009-20. doi: 10.1074/jbc.M110.180208.

50. Sehgal K, Das R, Zhang L, Verma R, Deng Y, Kocoglu M, Vasquez J, Koduru S, Ren Y, Wang M, Couto S, Breider M, Hansel D, et al. Clinical and pharmacodynamic analysis of pomalidomide dosing strategies in myeloma: impact of immune activation and cereblon targets. Blood. 2015; 125:4042-51. doi: 10.1182/blood-2014-11-611426.

51. Storti P, Marchica V, Airoldi I, Donofrio G, Fiorini E, Ferri V, Guasco D, Todoerti K, Silbermann R, Anderson JL, Zhao W, Agnelli L, Bolzoni M, et al. Galectin-1 suppression delineates a new strategy to inhibit myeloma-induced angiogenesis and tumoral growth in vivo. Leukemia. 2016. doi: 10.1038/leu.2016.137. 